\title{
Triplex staples: DNA Double Strand Cross-linking at Internal and Terminal sites using Psoralen-containing Triplex-Forming Oligonucleotides
}

Hong Li, ${ }^{1}$ Victoria J. Broughton-Head, ${ }^{2}$ Guomei Peng, ${ }^{1}$ Vicki E.C. Powers,,${ }^{1}$ Matthew J. Ovens, ${ }^{2}$ Keith R. Fox ${ }^{2}$ and Tom Brown ${ }^{1 *}$

\section{Supplementary materials}

Table S1. Maldi-TOF results of oligonucleotide sequences

Figure S1. UV-melting profiles for the complex between TFO 7 and duplex 5.6.

Figure S2. UV-melting profiles for the complex between TFO 8 and duplex 5.6.

Figure S3. UV-melting profiles for the complex between TFO 9 and duplex $\mathbf{5 \cdot 6}$.

Figure S4. UV-melting profiles for the complex between TFO 10 and duplex 5.6.

Figure S5. Fluorescence emission spectra of TFO 8 when complexed with duplex $\mathbf{5 \cdot 6}$ after various emission times.

Figure S6. Fluorescence emission spectra of TFO 9 when complexed with duplex $\mathbf{5 . 6}$ after various emission times.

Figure S7. Fluorescence emission spectra of TFO 10 when complexed with duplex $\mathbf{5 \cdot 6}$ after various emission times. 
Table S1. Maldi-TOF results of oligonucleotide sequences. Pso indicates 5'-psoralen (4'-(methoxyhexyl)-4, 5', 8-trimethylpsoralen), while $\mathbf{T}^{\mathrm{Pso}}$ corresponds to 5-(6-O-levulinoylhex-1-ynyl)-2'-deoxyuridine attached psoralen. $\mathrm{M}$ and $\mathrm{P}$ correspond to 3-methyl-2-aminopyridine-2'-deoxyriboside and 5-(3-aminoprop-2-ynyl)deoxyuridine respectively. 9 and $\mathbf{1 0}$ contain a 3'-phosphate.

\begin{tabular}{|c|c|c|c|c|}
\hline & \multicolumn{2}{|l|}{ Sequence } & \multirow{2}{*}{ 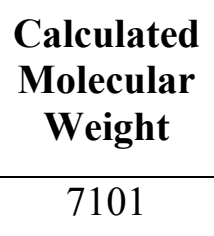 } & \multirow{2}{*}{$\begin{array}{c}\text { Observed } \\
\text { Molecular } \\
\text { Weight }\end{array}$} \\
\hline & 5'-TCATAGAGAATAAAGATATAGGC-3' & 5 & & \\
\hline D & 3'-AGTATCTCTTATTTCTATATCCG-5' & 6 & 6954 & 6955 \\
\hline \multirow{6}{*}{ TFOs } & 5'-TCTCTTGTTTCT-3' & 7 & 3571 & 3571 \\
\hline & 5'-pso-TCTCTTGTTTCT-3' & 8 & 3991 & 3989 \\
\hline & 5'-TCTCTTGTTTCT ${ }^{\mathrm{pso}}-\mathrm{p}-3^{\prime}$ & 9 & 4151 & 4152 \\
\hline & 5'-pso-TCTCTTGTTTCT ${ }^{\mathrm{pso}}$-p-3' & 10 & 4572 & 4572 \\
\hline & 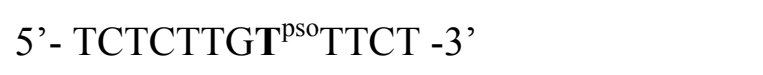 & 11 & 4071 & 4072 \\
\hline & 5'-pso-TMTMTPGPTPMT-3' & 12 & 4096 & 4097 \\
\hline
\end{tabular}




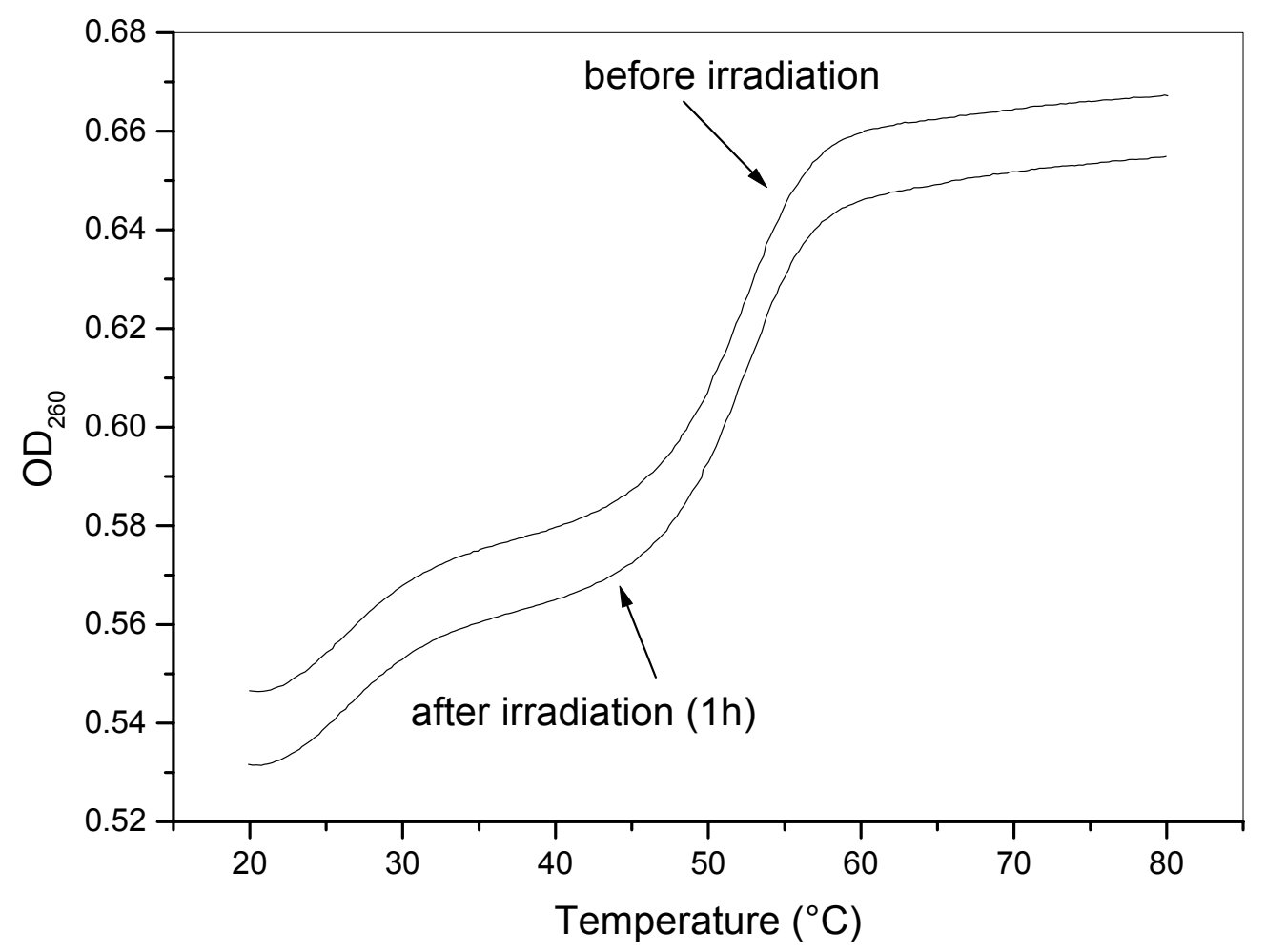

Figure S1. UV-melting profiles for the complex between TFO 7 and duplex 5.6. The reaction was performed in $50 \mathrm{mM}$ sodium acetate, $200 \mathrm{mM} \mathrm{NaCl}$, pH 5.0 with a duplex concentration of $1 \mu \mathrm{M}$ and $10 \mu \mathrm{M}$ TFO. 


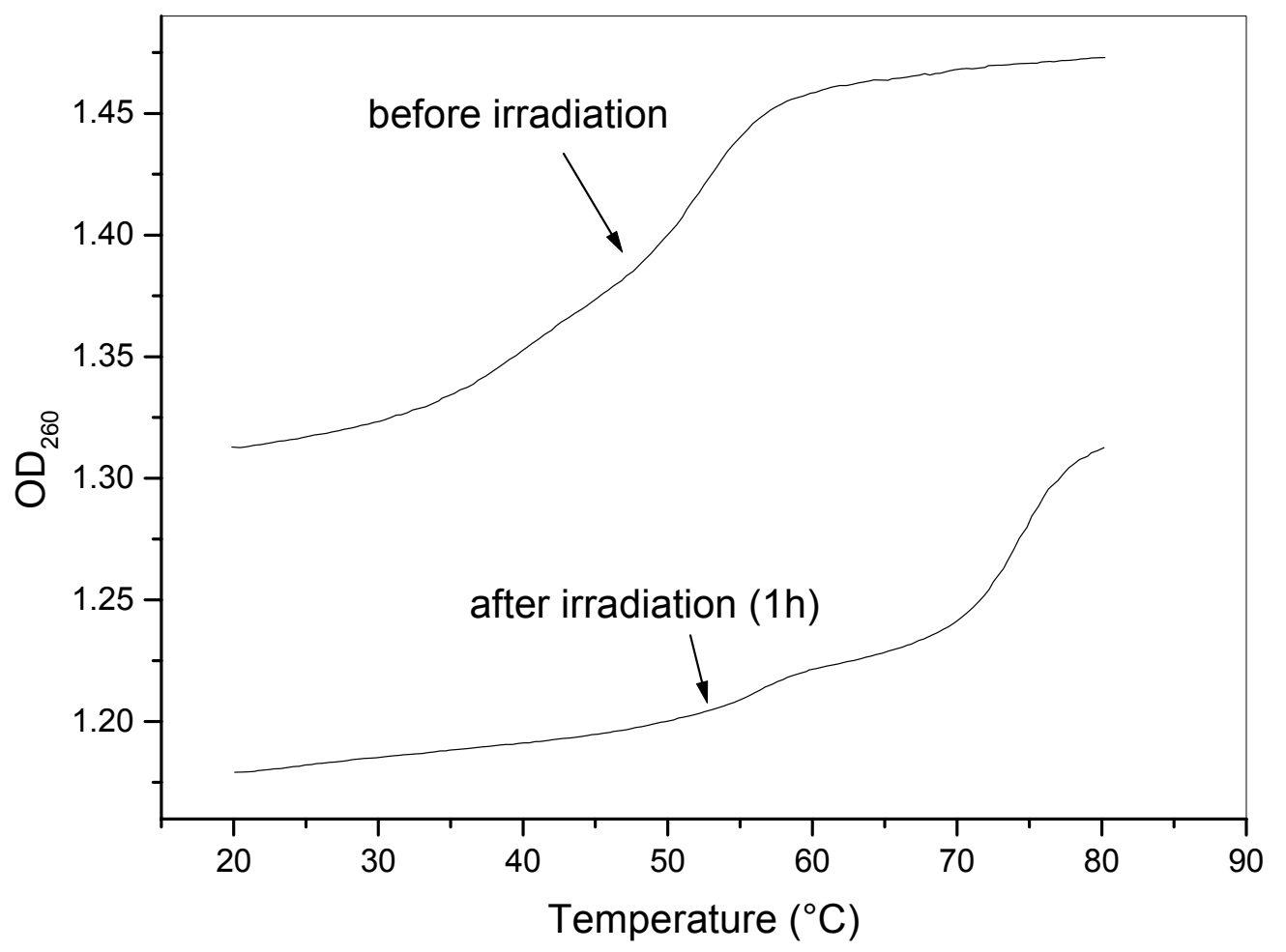

Figure S2. UV-melting profiles for the complex between TFO 8 and duplex 5.6. The reaction was performed in $50 \mathrm{mM}$ sodium acetate, $200 \mathrm{mM} \mathrm{NaCl}$, pH 5.0 with a duplex concentration of $1 \mu \mathrm{M}$ and $10 \mu \mathrm{M}$ TFO. 


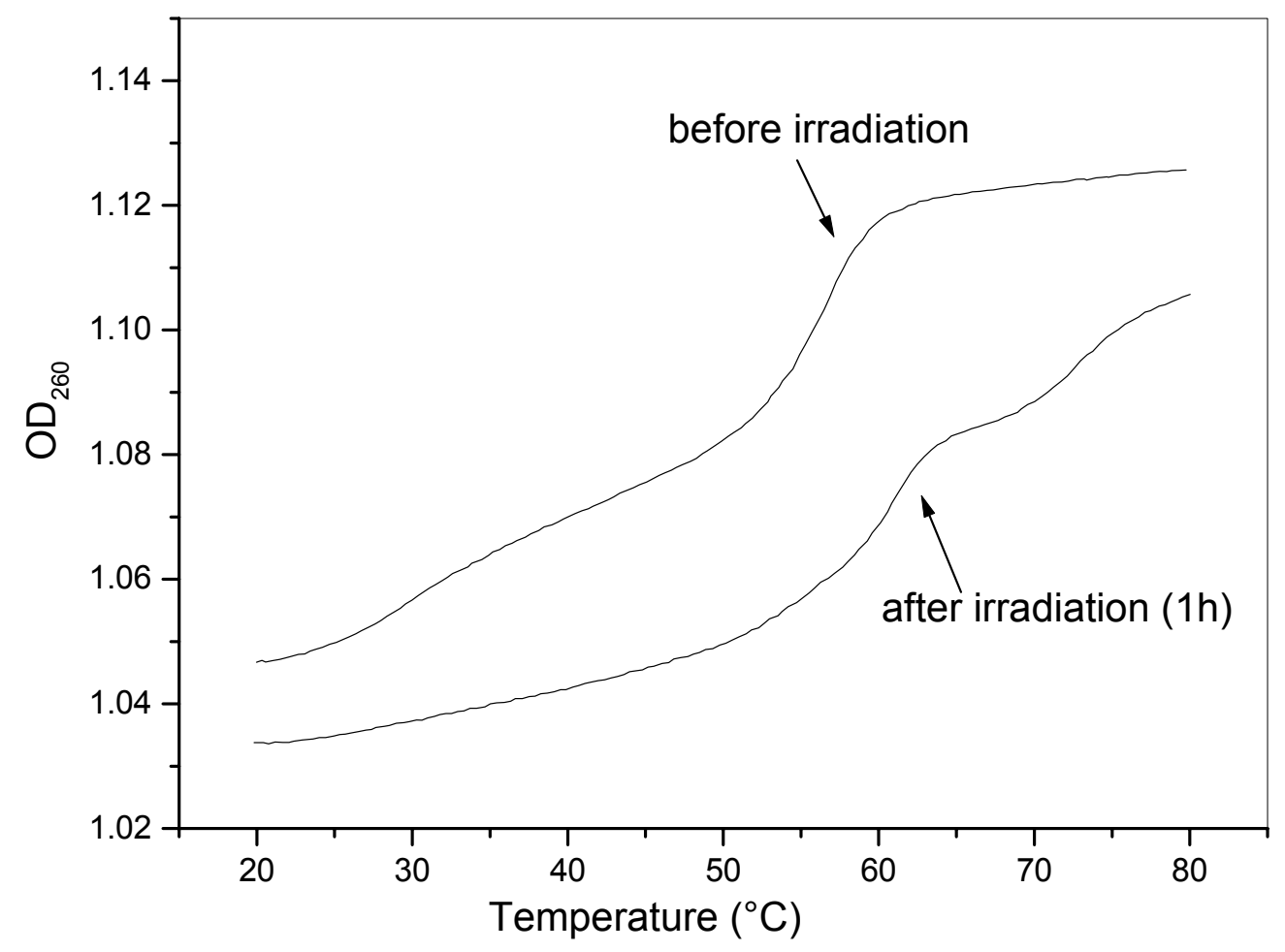

Figure S3. UV-melting profiles for the complex between TFO 9 and duplex 5.6. The reaction was performed in $50 \mathrm{mM}$ sodium acetate, $200 \mathrm{mM} \mathrm{NaCl}$, pH 5.0 with a duplex concentration of $1 \mu \mathrm{M}$ and $10 \mu \mathrm{M}$ TFO. 


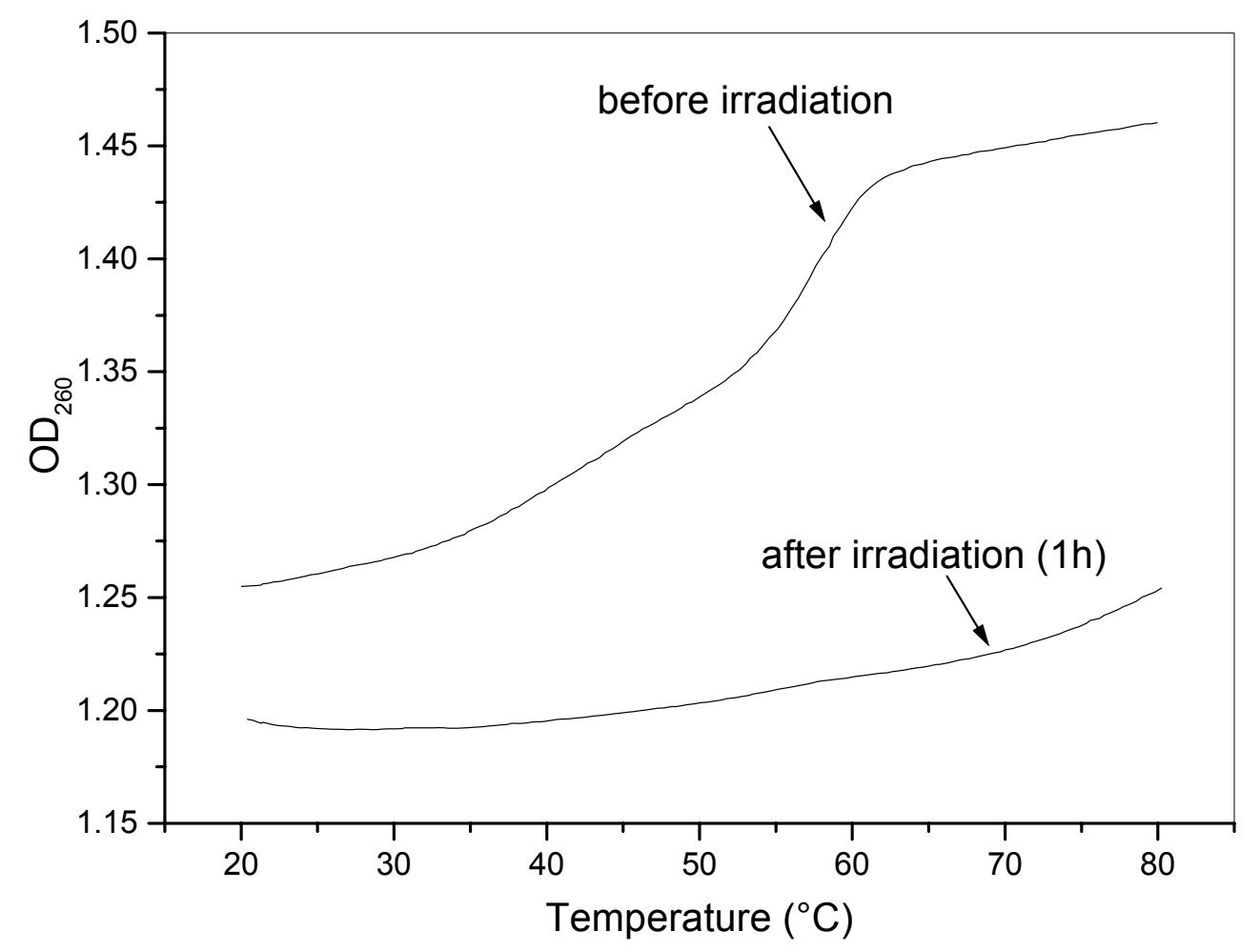

Figure S4. UV-melting profiles for the complex between TFO 10 and duplex 5.6. The reaction was performed in $50 \mathrm{mM}$ sodium acetate, $200 \mathrm{mM} \mathrm{NaCl}$, pH 5.0 with a duplex concentration of 1 $\mu \mathrm{M}$ and $10 \mu \mathrm{M}$ TFO. 


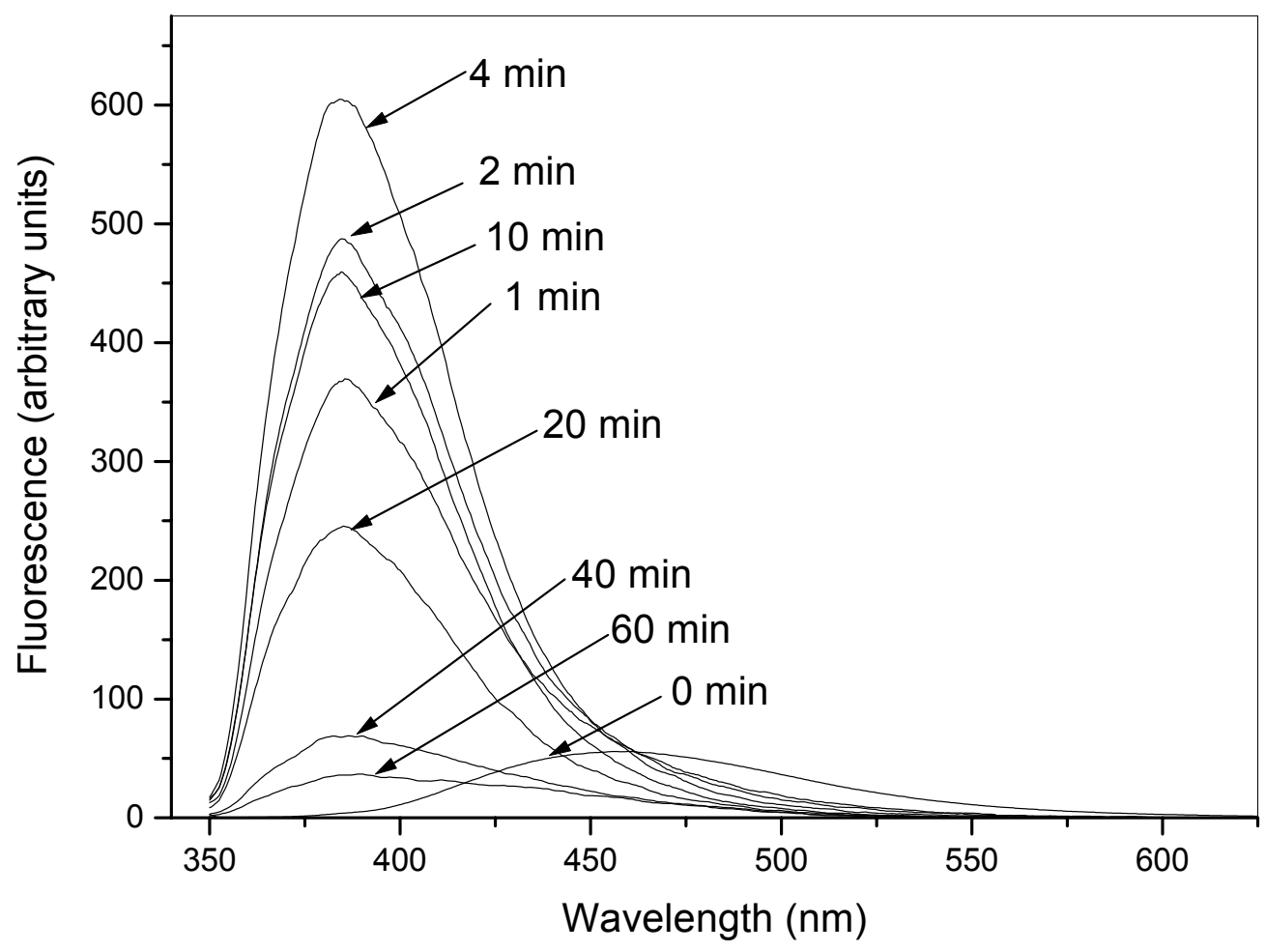

Figure S5. Fluorescence emission spectra of TFO 8 when complexed with duplex $\mathbf{5 \cdot 6}$ after various emission times. The reaction was performed in $50 \mathrm{mM}$ sodium acetate, $200 \mathrm{mM} \mathrm{NaCl}, \mathrm{pH}$ 5.0 with a duplex concentration of $5 \mu \mathrm{M}$ and $1 \mu \mathrm{M}$ TFO. 


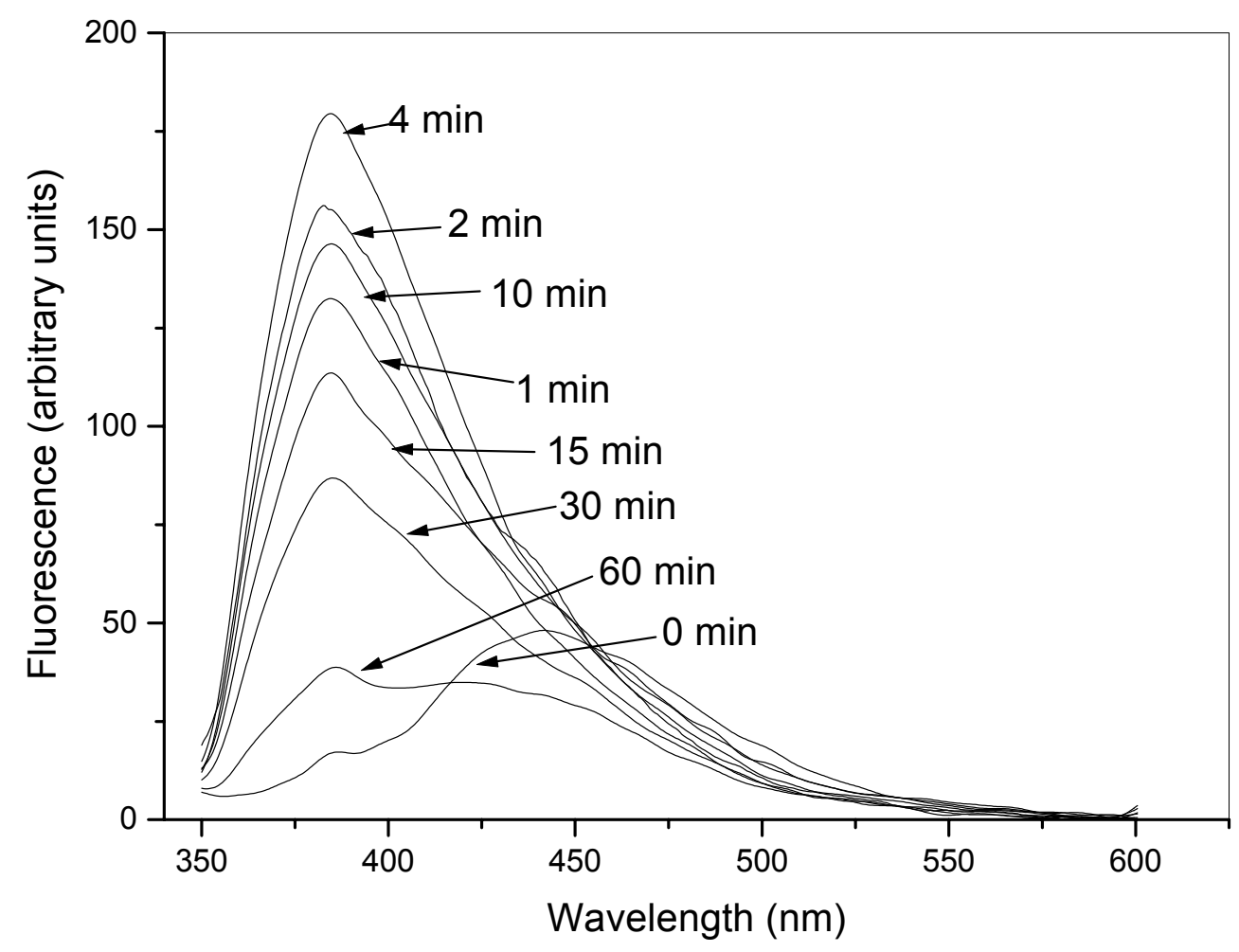

Figure S6. Fluorescence emission spectra of TFO 9 when complexed with duplex $\mathbf{5 \cdot 6}$ after various emission times. The reaction was performed in $50 \mathrm{mM}$ sodium acetate, $200 \mathrm{mM} \mathrm{NaCl}, \mathrm{pH}$ 5.0 with a duplex concentration of $5 \mu \mathrm{M}$ and $1 \mu \mathrm{M}$ TFO. 


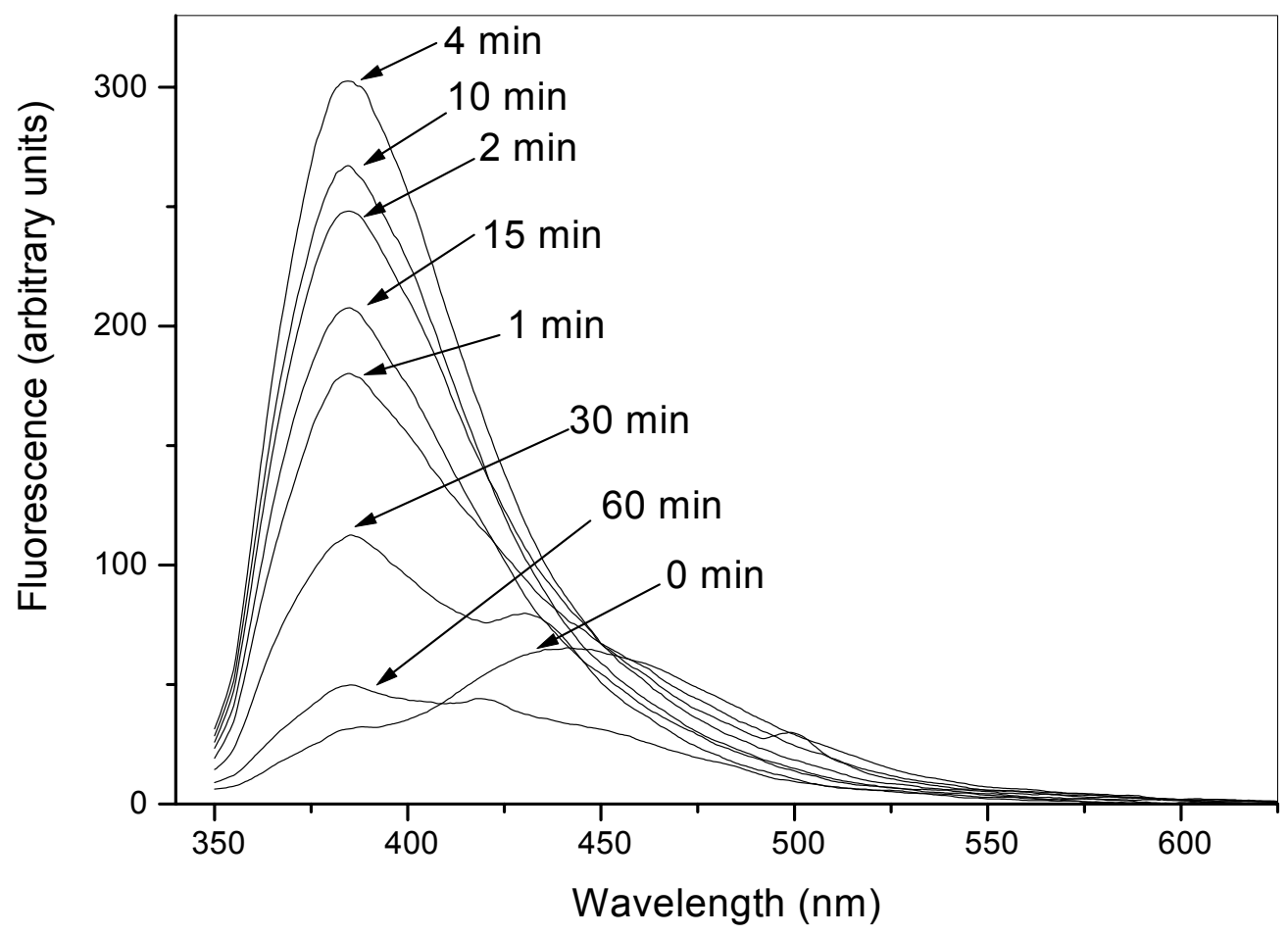

Figure S7. Fluorescence emission spectra of TFO 10 when complexed with duplex $\mathbf{5 \cdot 6}$ after various emission times. The reaction was performed in $50 \mathrm{mM}$ sodium acetate, $200 \mathrm{mM} \mathrm{NaCl}, \mathrm{pH}$ 5.0 with a duplex concentration of $5 \mu \mathrm{M}$ and $1 \mu \mathrm{M}$ TFO. 